Vol. 8 No 1, Juni 2021

P-ISSN: 2460-0709, E-ISSN: 2685-6611

Available online: https://ejurnalunsam.id/index.php/jagris

\title{
Analisis Biaya Dan Keuntungan UMKM HHBK Sirup Mangrove Di Desa Kuala Langsa Kecamatan Langsa Barat Kota Langsa
}

\author{
Hari Sabna*, Rozalina², Fiddini Alham² \\ 1,2,3 Jurusan Agribisnis Fakultas Pertanian Universitas Samudra \\ email: fiddini.alham@gmail.com \\ Diterima: November 2020, Disetujui: Desember 2020, Diterbitkan: Desember 2020
}

\begin{abstract}
Abstrak
Penelitian ini bertujuan untuk mengetahui struktur biaya dan keuntungan dari UMKM (Usaha Mikro Kecil Menengah) HHBK (Hasil Hutan Bukan Kayu) sirup mangrove di Desa Kuala Langsa Kecamatan Langsa Barat Kota Langsa. Data yang digunakan adalah data primer yang diperoleh dari hasil wawancara langsung dengan anggota kelompok Perempuan Kuala Maju. Metode analisis menggunakan rumus Avarage total cost (ATC), Total fixed cost (TFC), Total variabel cost (TVC), Avarage fixed cost (AFC), Avarage variabel cost (AVC), Total cost (TC), Total revenue (TR), dan Keuntungan (П). Data yang digunakan yaitu besar biaya yang dikeluarkan selama satu bulan produksi. Hasil penelitian menunjukkan bahwa stuktur biaya yaitu, biaya tetap sebesar Rp 265.625/bulan, biaya variabel sebesar Rp 1.423.770/bulan, biaya tetap rata-rata $\operatorname{Rp~} 1.362$ /bulan, biaya variabel rata-rata $7.301 /$ bulan, biaya total rata-rata 8.663/bulan, penerimaan sebesar Rp 2.925.000/bulan dan Total biaya yang dikeluarkan sebesar Rp 1.689.395/bulan, sehingga diperoleh keuntungan sebesar Rp 1.235.605/bulan.
\end{abstract}

Kata Kunci:

Biaya, HHBK, Keuntungan, Sirup Mangrove, UMKM

\begin{abstract}
This study aims to analyse the Cost and Profit Structure of The UMKM (Micro Small snd Medium Enterspises) HHBK (Non Timber Forest Products) mangrove syrup in Kuala Langsa Village, Langsa Barat Distric, Langsa City. Data collection methods are primary data obtained from direct interviews with members of The Kuala Maju Women's group. Analyze using the formula Avarage Total Cost(ATC), Total Fixed Cost (TFC), Total Variable Cost (TVC), Avarage Fixed Cost (AFC), Avarage Variabel Cost (AVC), Total Cost (TC), Total Income (TR) and Profit $(\Pi)$. The data use is the large costs incurred during one month of production. The results showed that the costs tructure, fixed cost amounted to Rp 265.625/month, variable cost amounde to $\mathrm{Rp} 1.463 .370 /$ month, avarage fixed cost $\mathrm{Rp} 1.363 /$ month, avarage variable costs $\mathrm{Rp} 7.505 /$ month, avarage total cost $\mathrm{Rp} 8.877 / \mathrm{month}$, receipts of IDR $\mathrm{Rp}$ 2.925.000/month and total cost incurred of IDR Rp 1.730.995/month, so that income of IDR Rp 1.195.005/month is obtained.
\end{abstract}

Keywords:

Cost, HHBK, Profit, Sirup Mangrove, UMKM

How to Cite: Sabna, H., Rozalina dan F. Alham. (2020). Analisis Biaya Dan Kentungan UMKM HHBK Sirup Mangrove Di Desa Kuala Langsa Kecamatan Langsa Barat Kota Langsa. Jurnal Penelitian Agrisamudra. 8(1):30-36

DOI: $10.33059 /$ jpas.v8i1.3314

\section{Pendahuluan}

Hutan mangrove dunia pada tahun 2010 diperkirakan memiliki luas sekitar 15,2 juta Ha. Hutan mangrove Indonesia merupakan hutan mangrove terluas di dunia, yaitu 
sekitar 3,15 juta Ha atau 21\% dari luas hutan mangrove dunia. Empat negara yang memiliki luas hutan mangrove terbesar setelah Indonesia adalah Brazil 9\%, Australia 7\%, Meksiko 5\% dan Nigeria 5\% (ITTO, 2010).

Adapun hutan mangrove yang ada di Provinsi Aceh seluas $12262.5 \mathrm{Ha}$, dan salah satu kota yang terdapat hutan mangrove di Provinsi Aceh adalah Kota Langsa. luas hutan mangrove yang ada di Kota Langsa yaitu 5292.2 Ha (BPS Provinsi Aceh, 2017).

Hutan mangrove memiliki banyak kelebihan dan manfaat dari HHBK (Hasil Hutan Bukan Kayu) salah satunya dapat meminimalisir kegiatan yang dapat merusak hutan mangrove. Di Kota Langsa sendiri penebangan hutan mangrove masih menjadi kebiasaan penduduk setempat yang diolah menjadi kayu bakar. Hal ini mendesak pemerintah untuk membantu penduduk setempat dalam mengembangkan usaha mikro Hasil Hutan Bukan Kayu demi menjaga kelestarian hutan tersebut. Terdapat beberapa usaha kecil menengah di Desa Kuala Langsa, yang mengolah buah mangrove menjadi sirup, selai, batik, kerupuk, dll. UMKM di Desa Kuala Langsa sendiri masih memiliki keterbatasan dalam menganalisis struktur biaya serta keuntungan, sehingga penelitian ini menjadi penting untuk dilakukan.

\section{Metode Penelitian}

Penelitian dilakukan di Desa Kuala Langsa Kecamatan dalam jangka waktu 1 bulan yaitu Februari 2020. UMKM yang dipilih adalah Kelompok Perempuan Kuala Maju, karena kelompok. Metode yang digunakan adalah metode survey untuk memperoleh fakta dari gejala-gejala yang ada dan mencari keterangan-keterangan secara faktual, baik tentang sosial, ekonomi, politik dari suatu kelompok maupun suatu daerah (Nazir, 2013). Data yang dikumpulkan yaitu data primer dan data sekunder dengan wawancara terstruktur dan kuesioner.

Untuk menganalisis stuktur biaya pada UMKM HHBK sirup mangrove maka perlu diketahui stuktur biaya yang dikeluarkan selama pengoperasian produk sirup mangrove tersebut diantara nya: Total fixed cost (TFC), biaya variabel/ Total variabel cost (TVC), biaya total rata-rata/Avarage total cost (ATC), biaya variabel rata-rata/Avarage variabel cost (AVC), biaya tetap rata-rata/Avarage fixed cost (AFC)

Analisis Keuntungan

1) Biaya total

$$
\mathbf{T C}=\mathbf{T F C}+\mathbf{T V C}
$$

Keterangan: $\mathrm{TC}=$ Total cost (biaya total $) /(\mathrm{Rp})$

$\mathrm{TFC}=$ Total fixed cost (biaya tetap total) $/(\mathrm{Rp})$

TVC = Total variabel cost (biaya tidak tetap) $/(\mathrm{Rp})$

2) Penerimaan (TR)

$$
\mathbf{T R}=\mathbf{P} \times \mathbf{Q}
$$

Keterangan: $\mathrm{TR}=$ Total revenue (penerimaan total $) /(\mathrm{Rp})$

$\mathrm{P} \quad=$ Price per unit (harga jual per unit)/(Rp)

$\mathrm{Q}=$ Quantity (jumlah produksi per unit)/(unit)

3) Keuntungan/Income (П) 


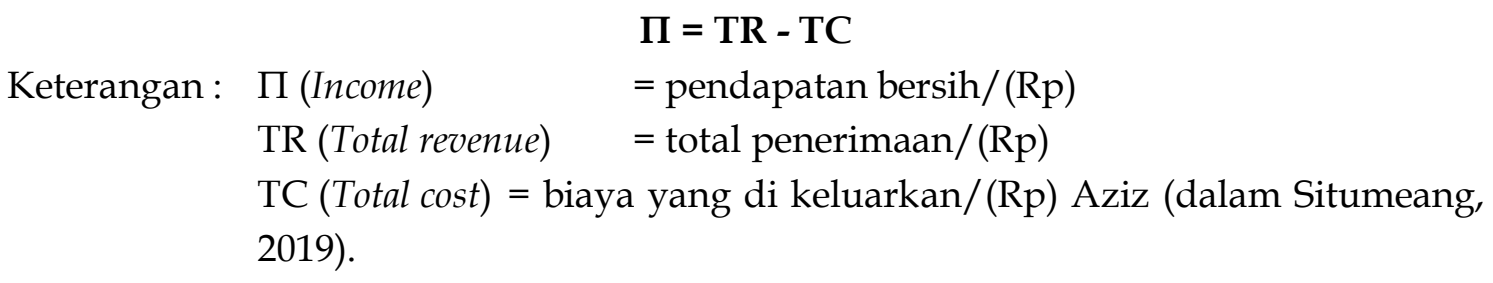

\section{Hasil dan Pembahasan}

\section{Analisis Struktur Biaya}

Setiap kegiatan produksi tidak dapat dipisahkan dari biaya, mulai dari persiapan alat, bahan baku, bahan pendukung hingga produk jatuh ke tangan konsumen membutuhkan biaya. Analisis biaya sangat diperlukan dalam sebuah usaha agar dapat diketahui pengeluaran dan menerimaan sehingga dapat diketahui pula keuntungan dalam usaha tersebut.

Data yang digunakan dalam penelitian ini adalah data selama satu bulan yang telah dikonversikan. Dalam satu bulan kelompok Perempuan Kuala Maju melakukan produksi sirup mangrove sebanyak tiga kali produksi. Dalam satu kali produksi menggunakan bahan baku buah pedada sebanyak $8 \mathrm{Kg}$ yang menghasilkan 65 botol sirup mangrove. jika dikonversikan ke dalam satu bulan maka buah pedada yang digunakan sebanyak $24 \mathrm{Kg}$ yang menghasilkan 195 botol sirup mangrove.

Berikut ini adalah uraian stuktur biaya dalam UMKM HHBK sirup mangrove pada kelompok Perempuan Kuala Maju.

1. Biaya Tetap

Biaya tetap adalah biaya yang tidak berubah meskipun barang atau jasanya meningkat maupun menurun. Biaya tetap tidak habis dalam sekali pakai dan tidak dipengaruhi oleh hasil dari usaha yang dijalankan. Biaya tetap pada UMKM HHBK sirup mangrove pada kelompok Perempuan Kuala Maju adalah biaya sewa tempat dan biaya penyusutan alat selama satu bulan. Berikut Tabel biaya tetap UMKM HHBK sirup mangrove pada kelompok Perempuan Kuala Maju.

Tabel 1. Biaya Tetap UMKM HHBK Sirup Mangrove Pada Kelompok Perempuan Kuala Maju, 2020

\begin{tabular}{clr}
\hline No. & \multicolumn{1}{c}{ Uraian } & Jumlah (Rp)/Bulan \\
\hline 1. & Sewa Tempat & 250.000 \\
2. & Biaya Penyusutan Alat & 15.625 \\
\hline & Total & $\mathbf{2 6 5 . 6 2 5}$ \\
\hline
\end{tabular}

Dari Tabel di atas total biaya tetap yang dikeluarkan oleh kelompok Perempuan Kuala Maju dalam satu bulan memproduksi sirup mangrove adalah sebesar Rp $265.625 /$ bulan. Biaya tetap meliputi biaya sewa tempat dan biaya penyusutan alat pada pembuatan sirup. Biaya sewa tempat sebesar Rp 250.000/bulan, meskipun kelompok Perempuan Kuala Maju tidak menyewa tempat melainkan pengolahan sirup mangrove diproduksi di rumah salah satu anggota dari mereka. Adapun luas 
tempat/ruang pembuatan sirup mangrove tersebut adalah $4 \times 5$ meter persegi. Dimana di tempat/ruang tersebutlah kegiatan pembuatan sirup mangrove dilakukan.

Buah pedada merupakan bahan baku dalam pembuatan sirup mangrove ini. Buah pedada dapat di panen dalam jangka waktu seminggu sekali yang ditandai dengan tekstur buah pedada yang sedikit lunak ketika ditekan dan buahnya berjatuhan dari pohon. Pada saat musim hujan buah pedada sangat berlimpah sedangkan pada saat musim kemarau melanda maka buah pedada pun sulit ditemukan. Kelompok Perempuan Kuala Maju memproduksi sirup mangrove tergantung pada ketersediaan buah pedada dan stok sirup yang belum terjual. Kelompok tersebut akan memproduksi sirup mangrove ketika bahan baku nya sudah tersedia. Namun harus diseimbangkan juga dengan stok sirup yang masih belum terjual. Jika masih banyak sirup magrove yang belum terjual maka produksi sirup mangrove pun tidak dilakukan. Biasanya sirup mangrove habis terjual dalam waktu satu sampai dua bulan. Selain itu, Kelompok Perempuan Kuala Maju juga melihat jangka waktu ke depannya, misalkan ke depannya akan datang musim kemarau maka mereka akan memproduksi sirup mangrove dengan jumlah yang banyak agar ketika musim kemarau tiba mereka tetap memiliki simpanan sirup mangrove untuk dijual. Sirup mangrove dapat bertahan hingga satu tahun meskipun tanpa pengawet, ini disebabkan karena pada proses pembuatannya sirup mangrove dimasak hingga benar-benar matang dan mengental.

Biaya penyusutan alat yaitu metode perhitungan masa pakai alat yang digunakan dalam proses produksi. Biaya penyusutan alat UMKM HHBK sirup mangrove pada kelompok Perempuan Kuala Maju sebesar Rp 15.625/bulan, adapun jenis alat-alat yang digunakan dalam proses pembuatan sirup mangrove adalah pisau, panci, ember, kompor, tabung gas, centong, talenan, kain penyaring, blender dan corong, untuk rincian harganya dapat dilihat.

2. Biaya Variabel

Biaya variabel adalah biaya yang besar-kecilnya dipengaruhi oleh produksi yang diperoleh (output). Produksi yang diperoleh biasanya berkaitan langsung dengan penggunaan faktor produksi (input) yang digunakan. Biaya variabel UMKM HHBK sirup mangrove pada kelompok Perempuan Kuala Maju meliputi biaya bahan-bahan pembuatan sirup mangrove dan biaya tenaga kerja yang digunakan, lebih rincinya dapat dilihat pada Tabel dibawah ini: 
Tabel 2. Biaya Variabel UMKM HHBK Sirup Mangrove Pada Kelompok Perempuan Kuala Maju, 2020

\begin{tabular}{clrrrr}
\hline No & \multicolumn{1}{c}{ Uraian } & Satuan & \multicolumn{1}{c}{ Jumlah } & Harga/Satuan & Total Harga (Rp) \\
\hline 1. & Buah Pedada & $\mathrm{Kg}$ & 24 & 5.000 & 120.000 \\
2. & Gula Pasir & $\mathrm{Kg}$ & 48 & 12.000 & 576.000 \\
3. & Air & Liter & 12 & 265 & 3.180 \\
4. & Bunga Rosella & Gram & 600 & 5.000 & 30.000 \\
5. & Botol Sirup & Buah & 195 & 1.142 & 222.690 \\
6. & Stiker & Buah & 195 & 500 & 97.500 \\
7. & Gas & Unit & 2 & 27.000 & 54.000 \\
& Biaya Tenaga & & & & 320.000 \\
8. & Kerja & orang & 5 & - & $\mathbf{1 . 4 2 3 . 7 7 0}$ \\
\hline
\end{tabular}

Dari Tabel di atas dapat dilihat total biaya variabel UMKM HHBK sirup mangrove pada kelompok Perempuan Kuala Maju adalah sebesar Rp 1.423.770/bulan. Dimana biaya tenaga kerja yang harus dibayar oleh kelompok Perempuan Kuala Maju dalam proses pembuatan sirup mangrove selama satu bulan yaitu sebesar Rp 320.000/bulan. Biaya tenaga kerja yang dipakai untuk pengumpul buah pedada dibayar berdasarkan jumlah buah pedada, untuk $1 \mathrm{~kg}$ buah pedada dibayar Rp 5.000. Biaya tenaga kerja pengupas buah pedada dibayar juga berdasarkan jumlah buah pedada, untuk $1 \mathrm{~kg}$ buah pedada yang dikupas dibayar Rp 2.000. Pada tenaga kerja memasak dan pengemasan sirup mangrove untuk $1 \mathrm{~kg}$ buah mangrove yang dimasak biasanya diabayar Rp 5.000. Namun dikarenakan memasak dan pengemasan sirup mangrove mereka lakukan sendiri, maka mereka tidak mengeluarkan biaya tenaga kerja untuk kegiatan ini.

3. Stuktur Biaya

Setelah menghitung biaya tetap dan biaya variabel maka dapat dihitung pula stuktur biaya pada UMKM HHBK sirup mangrove, lebih jelasnya dapat dilihat pada tabel dibawah ini:

Tabel 3. Stuktur Biaya UMKM HHBK Sirup Mangrove pada Kelompok Perempuan Kuala Maju, 2020

\begin{tabular}{|c|c|c|c|c|}
\hline \multirow[b]{2}{*}{ No. } & \multirow[b]{2}{*}{ Komponen Biaya } & \multirow{2}{*}{$\begin{array}{c}\text { Jumlah } \\
\text { (Rp)/Bulan }\end{array}$} & \multicolumn{2}{|c|}{$\%$} \\
\hline & & & Total & Biaya \\
\hline & Total Biaya Tetap & 265.625 & & 0,15 \\
\hline 1. & Biaya Sewa Tempat & 250.000 & & 0,14 \\
\hline 2. & Biaya Penyusutan Alat & 15.625 & & 0,00 \\
\hline & Total Biaya Variabel & 1.423 .770 & & 0,84 \\
\hline & Buah Pedada & 120.000 & & 0,07 \\
\hline 2. & Gula Pasir & 576.000 & & 0,34 \\
\hline 3. & Air & 3.180 & & 0,00 \\
\hline 4. & Bunga Rosella & 30.000 & & 0,01 \\
\hline
\end{tabular}




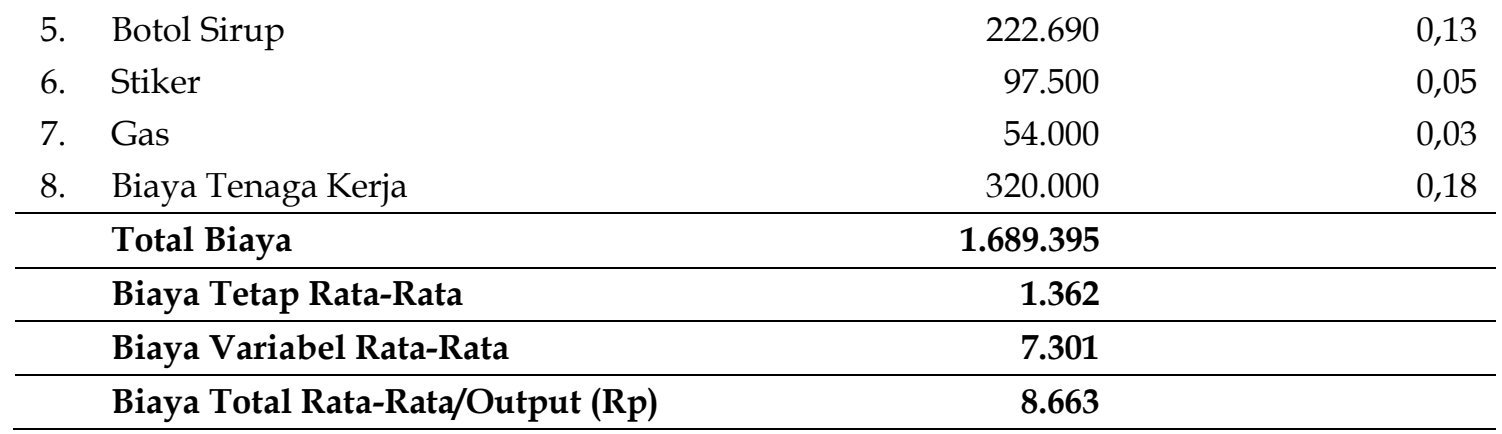

Dari Tabel di atas dapat dilihat total biaya tetap yang dikeluarkan sebesar Rp 265.625 / bulan dengan \% total biaya tetap sebesar 0,15. Kemudian Total biaya variabel yang dikeluarkan selama proses produksi yaitu sebesar Rp 1.423.770/ bulan dengan \% total biaya variabel sebesar 0,84 . Biaya tetap rata-rata diperoleh dari biaya tetap dibagi

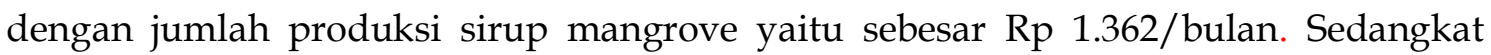
biaya variabel rata-rata diperoleh dari biaya variabel dibagi dengan jumlah produksi sirup mangrove yaitu sebesar Rp 7.301/bulan dan biaya total rata-rata untuk setiap output adalah sebesar Rp 8.663/bulan.

Adapun fungsi menghitung biaya rata-rata pada UMKM HHBK sirup mangrove adalah untuk melihat besarnya biaya rata-rata yang dikeluarkan selama satu bulan oleh Kelompok Perempuan Kuala maju di Desa Kuala Langsa.

4. Penerimaan dan Keuntungan

Kelompok Perempuan Kuala Maju yang melakukan UMKM HHBK sirup mangrove dapat mengetahui keuntungan dari usaha mereka dengan menghitung peneriamaan dan keuntungan yang diperoleh. Penerimaan diperoleh dari perkalian antara harga sirup mangrove per botol dengan jumlah produksinya. Sedangkan keuntungan diperoleh dari hasil pengurangan antara penerimaan dengan biaya total, Lebih jelasnya dapat dilihat pada tabel dibawah ini:

Tabel 4. Penerimaan dan Keuntungan UMKM HHBK Sirup Mangrove pada Kelompok Perempuan Kuala Maju, 2020

\begin{tabular}{lrrrrr}
\hline $\begin{array}{c}\text { Jenis } \\
\text { Produksi }\end{array}$ & $\begin{array}{c}\text { Harga } \\
\text { (Rp)/Unit }\end{array}$ & $\begin{array}{c}\text { Jumlah } \\
\text { Produksi } \\
\text { (Unit)/Bulan }\end{array}$ & $\begin{array}{c}\text { Penerimaan } \\
\text { (Rp)/bulan }\end{array}$ & $\begin{array}{c}\text { Total Biaya } \\
\text { (Rp)/bulan }\end{array}$ & $\begin{array}{c}\text { Keuntungan } \\
\text { (Rp)/bulan }\end{array}$ \\
\hline $\begin{array}{l}\text { Sirup } \\
\text { Mangrove }\end{array}$ & 15.000 & 195 & 2.925 .000 & 1.689 .395 & 1.235 .605 \\
\hline
\end{tabular}

Dari Tabel di atas dapat dilihat bahwa penerimaan yang diperoleh oleh kelompok Perempuan Kuala Maju pada UMKM HHBK sirup mangrove yang mereka usahakan yaitu sebesar Rp 2.925.000/bulan. Dan biaya total yang dikeluarkan sebesar Rp 1.689.395/bulan, biaya total ini diperoleh dari penjumlahan biaya tetap dengan biaya variabel. Dari perhitungan tersebut dapatlah diketahui keuntungan yang didapatkan oleh kelompok Perempuan Kuala Maju yaitu sebesar Rp 1.235.605/bulan. 
Besar keuntungan yang diperoleh tersebut yaitu Rp 1.235.605/bulan bagi anggota kelompok Perempuan Kuala Maju sudah cukup untuk menambah penghasilan. Keuntungan dari penjualan sirup mangrove akan dibagikan kepada anggota kelompok yang memasak dan mengemas sirup saja. Biasanya kegiatan memasak dan pengemasan sirup dilakukan oleh anggota kelompok secara bergantian. Untuk kegiatan tersebut dilakukan oleh tiga orang anggota. Sehingga keuntungan hanya dibagikan kepada tiga orang anggota yang melakukan kegiatan memasak dan pengemasan sirup mangrove.

\section{Simpulan}

Berdasarkan hasil penelitian yang telah dilakukan maka disimpulkan, berdasarkan hasil penjualan sirup mangrove pada UMKM HHBK mangrove milik kelompok Perempuan Kuala Maju diketahui stuktur biayanya yaitu, biaya tetap sebesar Rp 265.625/bulan, biaya variabel sebesar Rp 1.423,770/bulan, penerimaan sebesar Rp 2.925.000/bulan dan Total biaya yang dikeluarkan sebesar Rp 1.689.395/bulan. Kelompok Perempuan Kuala Maju memperoleh keuntungan sebesar Rp 1.235.605/bulan. Bahan baku berupa buah pedada sebanyak $24 \mathrm{~kg}$ yang diolah selama satu bulan dapat menghasilkan sirup mangrove sebanyak 195 unit dengan harga jual Rp 15.000/unitnya.

\section{Daftar Pustaka}

Badan Pusat Statistik Provinsi Aceh. (2017). Luas Mangrove Provinsi Aceh Menurut Kondisi pada Kabupaten/Kota 2014-2015, Aceh.

ITTO International Tropical Timber Organization. (2010). World Atlas of Mangrove

Sugiyono. (2015). Metode Penelitian Kombinasi (Mix Methods). Bandung: Alfabeta

Nazir, M. (2013). Metode Penelitian. Ghalia Indonesia. Bogor.

Sugiyono. (2015). Metode Penelitian Kombinasi (Mix Methods). Bandung: Alfabeta

Sugiyono. (2016). Metode Penelitian Kuantitatif, Kualitatif dan RED. Bandung: PT. Alfabet.

Sugiyono. (2017). Metode Penelitian Kuantitatif, Kualitatif, dan RED. Bandung: Alfabeta, $\mathrm{CV}$.

Situmeang, (2019). Analisis Finansial Produk Olahan Kerupuk Jeruju (Acanthus ilicifolius) Dan Sirup Pedada (Sonneratia caseolaris) di Desa Lubuk Kertang, Kecamatan Brandan Barat, Kabupaten Langkat. Jurnal Fakultas Kehutanan Universitas Sumatera Utara. Repositori Institusi USU. 